\title{
Substance Usage Start Timepoint
}

National Cancer Institute

\section{Source}

National Cancer Institute. Substance Usage Start Timepoint. NCI Thesaurus. Code C88006.

A point in time that indicates the beginning of substance usage. 